\title{
Epidemiological Challenges in Rare Bleeding Disorders: FVIII Inhibitor Incidence in Haemophilia A Patients-A Known Issue of Unknown Origin
}

\author{
Christine Keipert ${ }^{1, * \mathbb{D}}$, Ursula Drechsel-Bäuerle ${ }^{2}$, Doris Oberle ${ }^{2}$, Mirco Müller-Olling ${ }^{3}$ and Anneliese Hilger ${ }^{3}$ \\ 1 German Haemophilia Registry, Paul-Ehrlich-Institut, Federal Institute for Vaccines and Biomedicines, \\ 63225 Langen, Germany \\ 2 Safety of Medicinal Products and Medical Devices, Paul-Ehrlich-Institut, Federal Institute for Vaccines and \\ Biomedicines, 63225 Langen, Germany; Ursula.Drechsel-Baeuerle@pei.de (U.D.-B.); \\ Doris.Oberle@pei.de (D.O.) \\ 3 Hematology and Transfusion Medicine, Paul-Ehrlich-Institut, Federal Institute for Vaccines and Biomedicines, \\ 63225 Langen, Germany; Mirco.Mueller-Olling@pei.de (M.M.-O.); anneliese.hilger@pei.de (A.H.) \\ * Correspondence: christine.keipert@pei.de
}

check for

updates

Citation: Keipert, C.; Drechsel-Bäuerle, U.; Oberle, D.; Müller-Olling, M.; Hilger, A. Epidemiological Challenges in Rare Bleeding Disorders: FVIII Inhibitor Incidence in Haemophilia A Patients-A Known Issue of Unknown Origin. Int. J. Environ. Res. Public Health 2021, 18, 225.

https://doi.org/10.3390/ijerph18010225

\begin{abstract}
There is a broad range of factor products approved in Germany for haemophilia A treatment. Since the introduction of recombinant coagulation factor VIII (FVIII) products in the 1990s, there has been substantial debate whether there is a difference in inhibitor incidence between single FVIII products or product classes. Neither haemophilia registries nor clinical studies, including a randomised controlled clinical trial, provided a consistent and definite answer. The reasons were mainly related to methodological challenges in conducting controlled studies in a rare disease. In this analysis, the most relevant epidemiological challenges and main problems were examined, including study bias, potential overlap of individual studies and advanced development of therapy and methods in the course of time. Meta-analyses on two levels showed that therapies using recombinant products resulted in different event rates when compared to plasma-derived products. These results are accompanied by substantial study heterogeneity evidenced by Cochran's $Q$ tests. Only three studies have been identified that meet the standards of current clinical guidance. To finally resolve this ongoing and disputable safety issue of replacement therapy, collaboration among registry owners, academia and regulators must be fostered.
\end{abstract}

Keywords: rare diseases; epidemiology; haemophilia A; inhibitor development

\section{Introduction}

Haemophilia A (HA) is a rare X-linked bleeding disorder caused by a mutation in the gene coding for coagulation factor VIII (FVIII). Annually about 250 newborns in Europe are diagnosed with the severe form of the disease, characterised by $<1 \%$ residual FVIII activity. Those patients are in need of treatment with exogenous FVIII purified from blood or biotechnologically manufactured, referred to as plasma-derived FVIII (pdFVIII) or recombinant FVIII (rFVIII), respectively. The most serious and challenging side effect in patients with severe HA is the development of inhibitors against FVIII, which occurs in around $30 \%$ of the previously untreated patients (PUPs), primarily within the first 50 exposure days (EDs) [1]. There is a broad range of factor products approved in Germany for HA treatment (Figure 1) and since the introduction of rFVIII in the 1990s, there has been substantial debate whether there is a difference in inhibitor incidence between FVIII products [2,3]. In particular, the immunogenicity of second or third generation rFVIII products, von-Willebrand (vWF) content in FVIII products and rFVIII products modified for half-life extension gave rise to concern [4]. Neither haemophilia registries [5] nor clinical studies performed in the frame of marketing authorisation [6] nor a randomised controlled trial (RCT) [7] provided a definite answer. The reason was the lack of a sufficient 
number of patients with this rare disease to enable statistically relevant conclusions based on individual products as well as methodological problems.

Several meta-analyses or reviews have been conducted to elaborate on the role of different FVIII products for inhibitor incidence in PUPs [8-10] without conclusive findings for distinct products. Two regulatory reviews in the European Union under Article 20 of Regulation (EC) No. 726/2004 [11,12] and Article 31 of Directive 2001/83/EC [13,14] could not finally clarify whether there is a differential risk between product classes or individual recombinant products. Subsequently, the Guideline on the FVIII core SmPC was revised to include inhibitor development as a very common side effect in PUPs [15]. The time relationship between FVIII product approval and triggered regulatory procedures for investigating the inhibitor incidence is demonstrated in Figure 1.

Several factors led to significant changes in the European Medicines Agency (EMA) guidelines for FVIII products [16,17] and finally to the deletion of the obligation to perform clinical trials in PUPs for marketing authorisation purposes:

1. A sufficient number of factor products had already been approved for which risks and side effects in the treatment of PUPs were known.

2. It was foreseeable that many products would be seeking marketing authorisation at the same time so that due to the limited number of PUPs, this competitive situation would prevent studies being able to recruit patients in a reasonable time.

3. The studies and meta-analyses already conducted showed that the results of these studies are difficult to compare with each other.

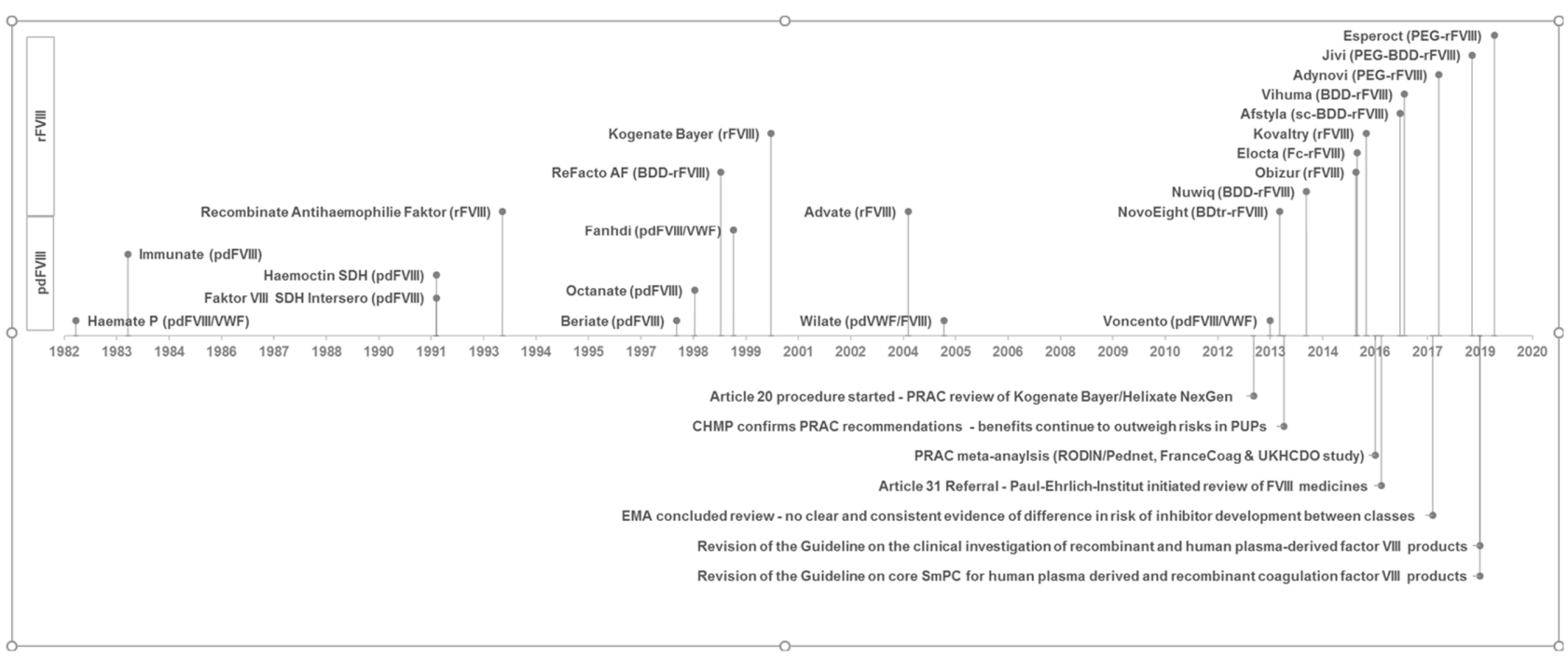

Figure 1. Time relationship between coagulation factor VIII (FVIII) product approval and triggered regulatory procedures for investigating the inhibitor incidence. License dates of human plasma-derived FVIII products (pdFVIII) and recombinant FVIII products (rFVIII) with marketing authorisation valid in Germany according to [18] are shown in the lower and upper area above the timeline. Qualitative product description is also given in brackets. VWF: von Willebrand factor, sc: single-chain, BDD/BDtr: B-domain deleted/truncated, PEG: PEGylated, Fc: Fc fusion protein.

We performed a systematic review of interventional and non-interventional studies and meta-analyses addressing inhibitor development in PUPs with severe HA. We hypothesise that, despite the number of patients involved in the respective studies being sufficient for statistical analyses, the risk of study bias and unmeasured confounding affect the meaningfulness of the calculation of inhibitor incidences. Therefore, we calculated combined inhibitor rates for plasma-derived and recombinant products for a carefully selected number of studies. 


\section{Materials and Methods}

\subsection{Study Selection}

A protocol for the review was pre-specified and registered on PROSPERO. The search was designed to be as sensitive as possible. Both published and unpublished reports were considered. All types of studies were eligible. Studies were identified by searching electronic databases (MEDLINE, the Cochrane Controlled Trials Register, EMBASE, BIOSIS) from 1946 to 30.05.2018. The following terms were used for the search: factor viii, hemophilia a, previously untreated, minimally treated (see search example in Supplement File S1). Articles from scanning reference lists of papers and reviews were also included. No limits were applied for language, and non-English papers have been translated where possible. Two authors conducted title and abstract screening independently. Those references that were not considered relevant by both reviewers were excluded from the review. Following criteria were applied:

(1) Is this a primary study?

(2) Was a FVIII product administered to a PUP or MTP (minimally treated patient)?

(3) Did the study examine the risk of Factor VIII inhibitor development?

Full texts for the remaining references were obtained, and eligibility was checked by two individuals according to the criteria mentioned above.

\subsection{Data Collection}

Data extraction tables and forms were developed to standardise the information extracted from each of the eligible studies. The following data from each included report were extracted: author and publication year, study location, recruitment period, planned period of patient follow-up, study design (controlled/uncontrolled, interventional/noninterventional, prospective/retrospective), FVIII product administered (type, subtype and brand name, vWF content), number of PUPs and MTPs included, definition of severity, number of PUPs/MTPs with a defined severity, number of inhibitors, number of PUPs/MTPs with inhibitor development, number of patients with high titre (>5 BU)/lowtitre/transient inhibitor, frequency of inhibitor testing specified, considered risk factors (race, genetics, family history, intensity of treatment, age), statistics (descriptive, hazard rate, Kaplan-Meier, other). Parameters were collected according to the Guideline on the clinical investigation of recombinant and human plasma-derived factor VIII products (ClinGL, [17]) ( $\geq 50$ PUPs included (MTPs not counted), follow-up $\geq 50$ EDs, severe haemophilia defined as $<1 \%$ FVIII:C, (the Nijmegen modification of) Bethesda method used, inhibitor testing frequency defined and according to the ClinGL). Two independent researchers crosschecked extracted data.

\subsection{Data Analysis}

Biases reflect inadequacies in the design or conduct of a study and may affect the validity of the findings. Biases have to be assessed and accounted for in studies. Therefore, for individual studies, a "Risk of bias" table for each interventional and observational study according to reference [19] was completed. The reviewers were guided by signaling questions and required to make a judgement on the level of each type of bias found within the study.

Risks of bias due to confounding, selection, information, reporting, departure from intervention, and missing data have been assessed as low, moderate or serious. The authors identified the following relevant confounders that may introduce a bias if these confounders were not considered for the analysis by stratification and adjustment: age at first FVIII exposure, intensity of FVIII treatment, discrimination of treatment: prophylaxis or on demand, risk factors for inhibitors: ethnicity, severity, family history and genetics.

Risk of overlap of individual studies: The risk of overlap of individual studies was evaluated depending on centres respectively countries where the trial was performed, the recruitment period and the investigators of the study, e.g., if there were several publications with the same product, for all studies with a comparable number of patients, published over 
several years from the same investigators in the same countries, it could not be excluded that these publications are based on the same cohort of patients.

\subsection{Statistical Analysis}

In addition to a narrative synthesis of the study data, two meta-analyses were performed. Eligible for inclusion in the first meta-analysis were studies in PUPSs with severe disease (FVIII $<1 \%$ ) for whom data on the development of any titre inhibitors after administration of FVIII products were provided, whereas in the second meta-analysis only studies were eligible that fulfilled all parameters specified in the ClinGL.

For each eligible study and product investigated, event rates (number of PUPs with any or high titre inhibitors/number of PUPs recruited) with corresponding $95 \%$ confidence intervals (CI) were calculated. Combined event rates were estimated by FVIII product type (plasma-derived; recombinant 1 , generation full length; recombinant 2 , generation full-length; recombinant 2, generation B domain deleted; recombinant 3, generation fulllength; recombinant 3 , generation $B$ domain deleted; recombinant not further specified). In addition, an overall combined event rate was computed. A random-effects model was used because of the anticipated clinical heterogeneity of the studies.

Heterogeneity was assessed using the Q-test, which informs about the presence versus the absence of heterogeneity and the $\mathrm{I}^{2}$ statistic quantifying the extent of heterogeneity [20]. In addition, as an estimate of the between-study variance in a random-effects meta-analysis, tau-squared $\left(\tau^{2}\right)$ was computed.

The meta-analyses were performed using the software Comprehensive Meta-Analysis, version 2.2.064 (Biostat, Englewood, NJ, USA).

\section{Results}

\subsection{Study Selection}

A total of 5687 records were identified through the electronic literature search. After the exclusion of duplicates, the title and abstract of 5453 records were screened, and 281 records were identified as potentially relevant for the study. The further screening and inclusion process is shown in Figure 2. The 80 publications identified as eligible in the final assessment were compared, and those covering the same patient population (e.g., the same study described in yearly updated publications) summarised. This finally led to 38 primary publications.

\subsection{Relevant Publications According to the Parameters Demanded in the ClinGL}

Taking the parameters according to the ClinGL [17] into account, the following numbers were identified: 28 publications described a population of a minimum of 50 PUPs, 23 publications had a follow-up of 50 EDs or more, in 26 publications, severe HA was defined as FVIII:C < 1\%, 34 publications reported that the Bethesda assay (or after 1995 the Nijmegen modification of this assay) was used, and in 11 publications a schedule for testing for inhibitors was defined prospectively. The combination of these conditions resulted in three publications that were in accordance with the ClinGL, which were, therefore, considered the most appropriate comparison groups. (Figure 3) $[7,21,22]$.

\subsection{Risk of Bias in Individual Studies}

The completion of a "Risk of bias" table for each study according to Sterne et al. [19] led to the following result: Overall, the risk of bias for the 38 primary publications was rated low to serious. However, for some studies, little or no information was available regarding bias (Table 1). The quality of studies was reviewed in relation to the presence of potential confounders that could hamper the interpretation of the results. With respect to bias by confounding, the following factors were considered: discrimination of treatment: prophylaxis or on demand ( $\mathrm{n}=22$ studies), FVIII gene mutation testing ( $\mathrm{n}=18$ studies), severity of HA ( $\mathrm{n}=38$ studies), human leukocyte antigen (HLA) genotype testing $(\mathrm{n}=1$ study), ethnicity ( $\mathrm{n}=28$ studies), genetics $(\mathrm{n}=19$ studies), family history $(\mathrm{n}=21$ studies $)$, intensity of 
treatment ( $\mathrm{n}=28$ studies) and age ( $\mathrm{n}=38$ studies). In addition, whether an adjustment for potential confounders with corresponding regression analyses was performed in the studies was checked, with the result that Cox proportional hazard models with time-dependent variables were applied to 11 studies. An overview of the underlying rating process can be found in the Supplemental Data (File S3). Of note, interventional studies might also be subject to a selection bias if PUPs were predominantly included. This might hinder the inclusion of patients who were born in families where HA was previously unknown and will only be detected in an emergency (around 50\% of PUPs) or patients with peak treatment as the first treatment.

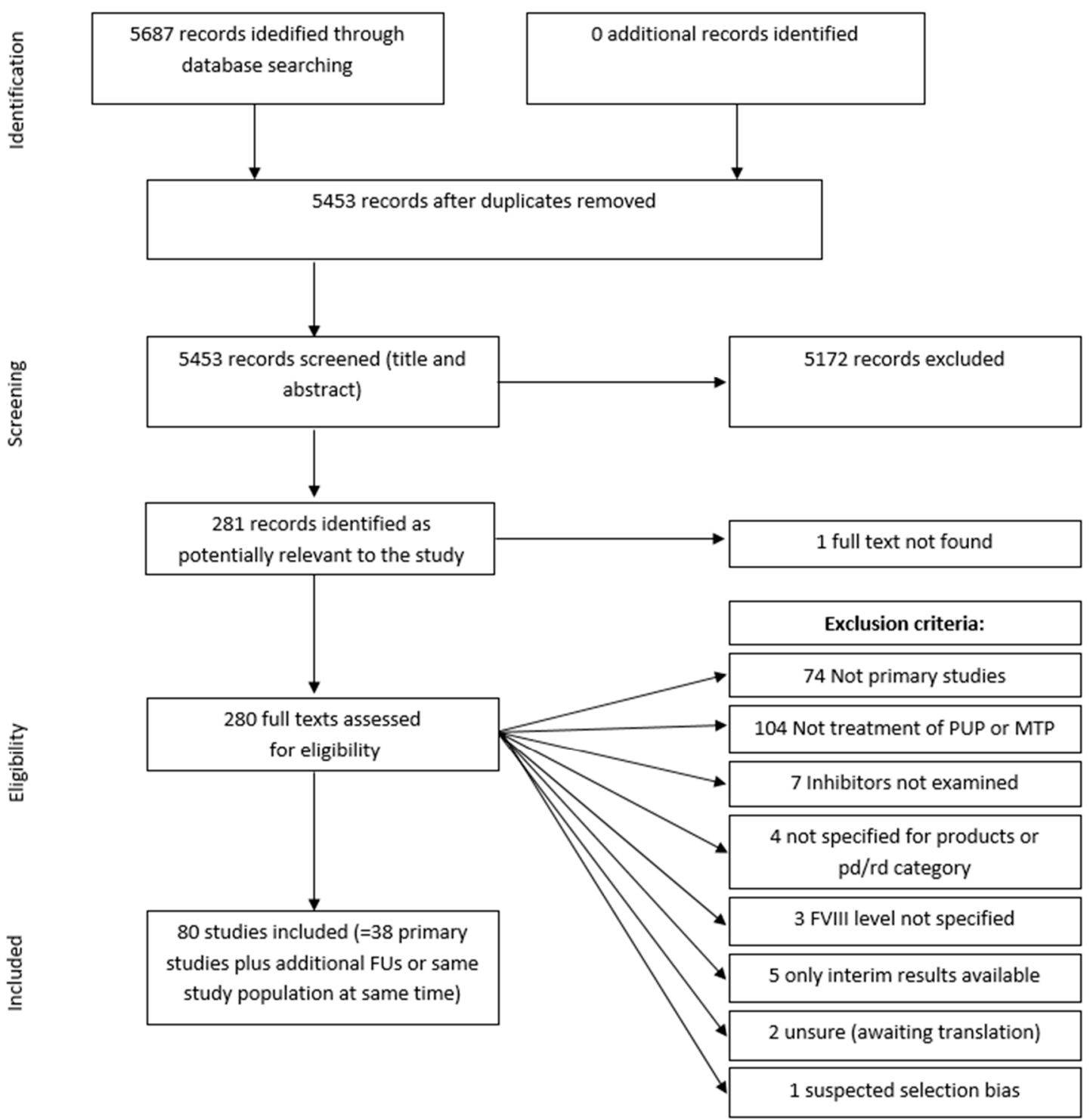

Figure 2. Flow of information from screening and inclusion process. 


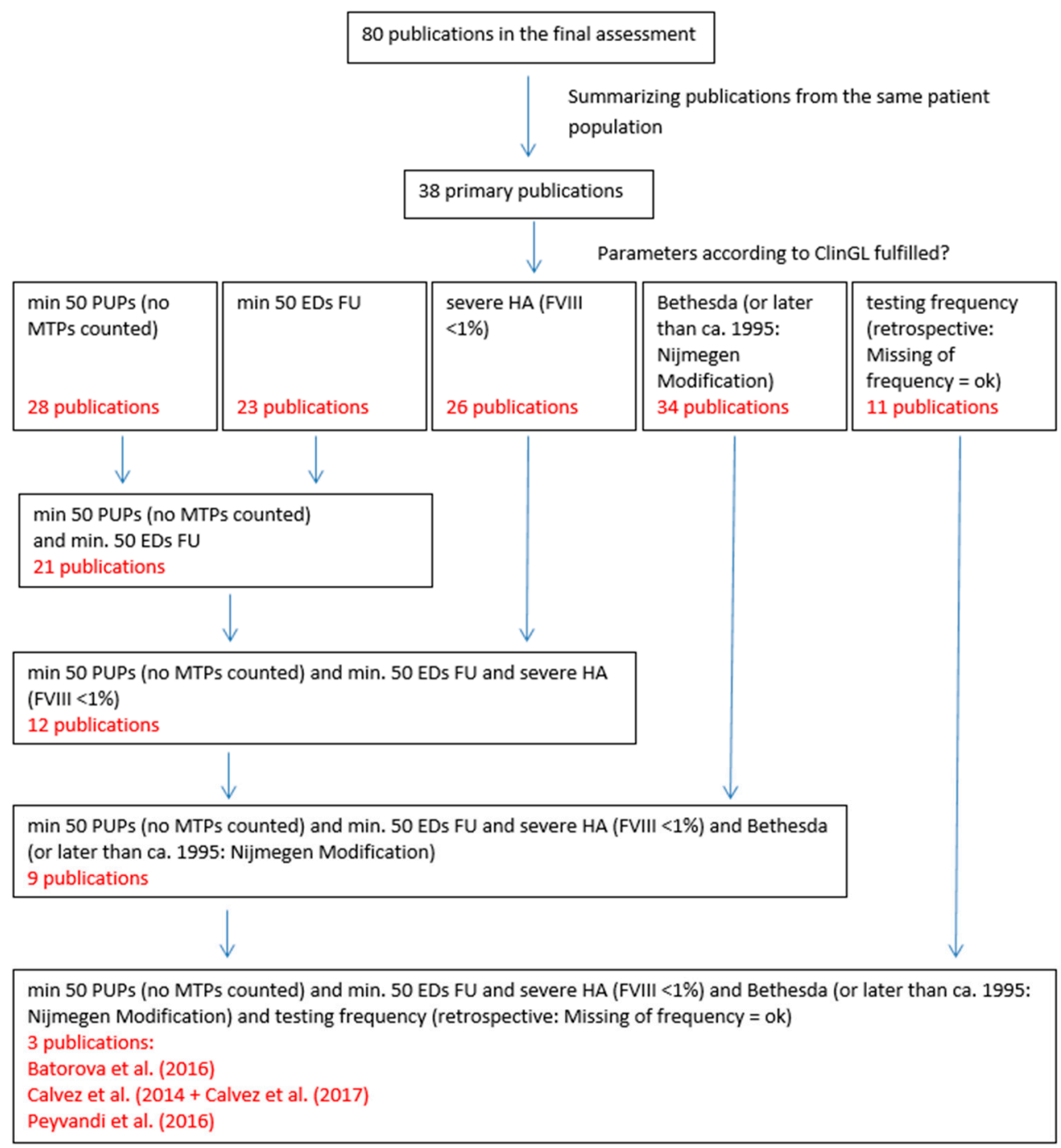

Figure 3. Relevant publications according to the parameters demanded in the ClinGL. A table of these 80 publications and the assessment process can be found in the Supplement to this paper (File S2).

\subsection{Potential for Overlap of Individual Studies}

The potential for overlap of the individual studies was evaluated depending on centres respectively countries where the trial was performed, recruitment period, and investigators. The assumed potential overlap of study populations is shown in Figure 4.

The figure demonstrates that studies evaluating a single factor concentrate often generate several publications over time. If such publications are to be included in a meta-analysis, it must be clear that the patient numbers cannot be added up but only supplemented. Determining whether publications are based on the same cohort of patients can be easier if the same authors publish the supplementary information (see Octanate) and difficult if not impossible to find out if a group of researchers is conducting the study and the first authors frequently change (see ReFacto, Kogenate, Recombinate, Advate). It could also be shown that data from registries are more often used in various publications, either by extracting and publishing data from a single factor product or by performing an analysis of all factor products included in the registry. It is important that in a literature meta-analysis, these numbers are not added up, but that care is taken to detect and avoid possible overlap. 
Table 1. Risk of bias in individual studies.

\begin{tabular}{|c|c|c|c|c|c|c|}
\hline Publication & $\begin{array}{l}\text { Risk of Confounding } \\
\text { Bias }\end{array}$ & Risk of Selection Bias & $\begin{array}{l}\text { Risk of Bias Due to } \\
\text { Departure from } \\
\text { Interventions }\end{array}$ & $\begin{array}{l}\text { Risk of Bias Due to } \\
\text { Missing Data }\end{array}$ & $\begin{array}{c}\text { Risk of Information } \\
\text { Bias }\end{array}$ & $\begin{array}{c}\text { Risk of Reporting } \\
\text { Bias }\end{array}$ \\
\hline \multicolumn{7}{|c|}{ Risk of bias for interventional studies } \\
\hline Auerswald et al., 2012 [23] & low & moderate & moderate & low & moderate & low \\
\hline Auerswald et al., 2015 [24] & moderate & low & low & low & moderate & low \\
\hline Batorova et al., 2016 [21] & moderate & low & low & moderate & moderate & low \\
\hline Biasi et al., 1994 [25] & serious & low & no information & moderate & moderate & low \\
\hline Bray et al., 1994 [26] & serious & low & low & moderate & moderate & low \\
\hline Courter et al., 2001 [27] & moderate & low & low & moderate & moderate & low \\
\hline ElAlfi et al., 2000 [28] & serious & low & low & moderate & serious & low \\
\hline Gouw et al., 2013 [5] & low & low & low & low & moderate & low \\
\hline Guérois et al., 1995 [29] & moderate & no information & no information & no information & moderate & low \\
\hline Klukowska et al., 2018 [30] & low & low & low & low & low & low \\
\hline Kreuz et al., 2005 [31] & low & low & low & low & low & low \\
\hline Kreuz et al., 2002 [32] & moderate & moderate & low & moderate & moderate & low \\
\hline Lusher and Salzmann 1990 [33] & moderate & low & low & serious & serious & low \\
\hline Lusher et al., 2004 [34] & moderate & low & moderate & moderate & moderate & moderate \\
\hline Schwartz et al., 1990 [36] & serious & low & no information & low & serious & moderate \\
\hline Yee et al., 1997 [37] & serious & low & no information & moderate & serious & moderate \\
\hline Yashioka et al., 2003 [38] & serious & no information & low & low & moderate & low \\
\hline \multicolumn{7}{|c|}{ Risk of bias for observational studies } \\
\hline Addiego et al., 1993 [39] & serious & no information & no information & no information & no information & low \\
\hline Blatny et al., 2003 [40] & serious & moderate & moderate & moderate & moderate & low \\
\hline Calvez et al., 2014 and 2018 [22,41] & low & low & low & low & moderate & low \\
\hline Chalmers et al., 2007 [42] & moderate & low & no information & no information & no information & low \\
\hline Collins et al., 2014 [43] & low & low & low & low & low & low \\
\hline Fischer et al., 2015 [44] & serious & no information & no information & low & no information & low \\
\hline Goudemand et al., 2006 [45] & moderate & moderate & no information & no information & no information & low \\
\hline Gouw et al., 2007 [46] & low & low & low & low & no information & low \\
\hline Gringeri et al., 2000 [47] & serious & no information & no information & no information & no information & no information \\
\hline
\end{tabular}


Table 1. Cont.

\begin{tabular}{|c|c|c|c|c|c|c|}
\hline Publication & $\begin{array}{c}\text { Risk of Confounding } \\
\text { Bias }\end{array}$ & Risk of Selection Bias & $\begin{array}{c}\text { Risk of Bias Due to } \\
\text { Departure from } \\
\text { Interventions }\end{array}$ & $\begin{array}{l}\text { Risk of Bias Due to } \\
\text { Missing Data }\end{array}$ & $\begin{array}{c}\text { Risk of Information } \\
\text { Bias }\end{array}$ & $\begin{array}{c}\text { Risk of Reporting } \\
\text { Bias }\end{array}$ \\
\hline Gringeri et al., 2006 [48] & serious & low & no information & moderate & moderate & low \\
\hline Maak et al., 2012 [50] & serious & no information & no information & no information & no information & low \\
\hline Mancuso et al., 2012 [51] & low & low & low & moderate & serious & low \\
\hline Musso et al., 2008 [52] & moderate & low & moderate & moderate & moderate & low \\
\hline Oldenburg et al., 2010 [53] & moderate & no information & no information & no information & no information & low \\
\hline Strauss et al., 2011 [55] & moderate & no information & low & no information & moderate & low \\
\hline Vepsäläinen et al., 2016 [56] & low & no information & moderate & moderate & no information & low \\
\hline Vézina et al., 2014 [57] & moderate & low & low & low & moderate & low \\
\hline
\end{tabular}




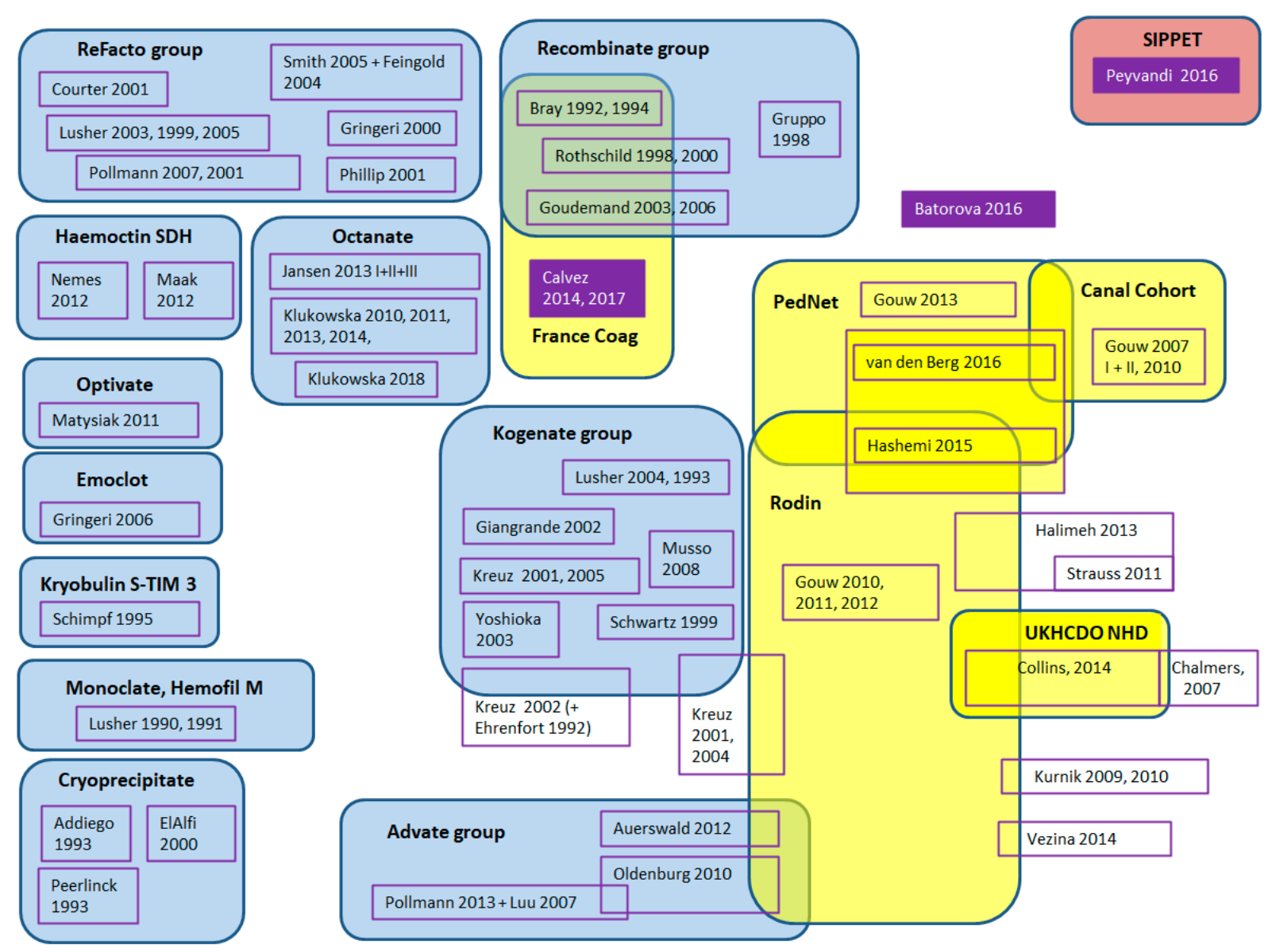

Figure 4. Risk of overlap of individual studies-Studies evaluating a single factor concentrate are summarised under the name of the factor concentrate in blue boxes. Studies originating from registry data are presented in yellow boxes and prospective trials in pink boxes. The three remaining relevant studies following the parameters demanded in the ClinGL are shown in purple.

\subsection{Time of Publication and Study Duration}

Recruitment for PUP studies took, on average, more than 10 years from study start to completion (Figure 5).

Such long periods have some drawbacks. First, HA treatment has made major improvements in the period covered here, including changes in the treatment regimen from on-demand to low or high dose prophylactic therapy. Second, laboratory methods varied by time, e.g., the Nijmegen modification of the Bethesda Assay was introduced. Third, several HA-related definitions have been refined, e.g., definitions of low and high titre as well as transient inhibitors or definitions of bleeding episodes. Finally, yet importantly, the concept for inhibitor testing was modified from a weekly or monthly testing schedule to a concept based on exposure days, which has been proven to describe the most vulnerable period for PUP inhibitor development more precisely. Hence, results from PUP studies with such long recruitment periods must be interpreted with caution because of changing methodological and medical standards during the conduct of the study. This is of particular concern if the therapy of later recruited PUPs is either no longer state-of-the-art or must be adapted by study amendments, so that data of recruited patients may differ dependent on their recruitment date. 


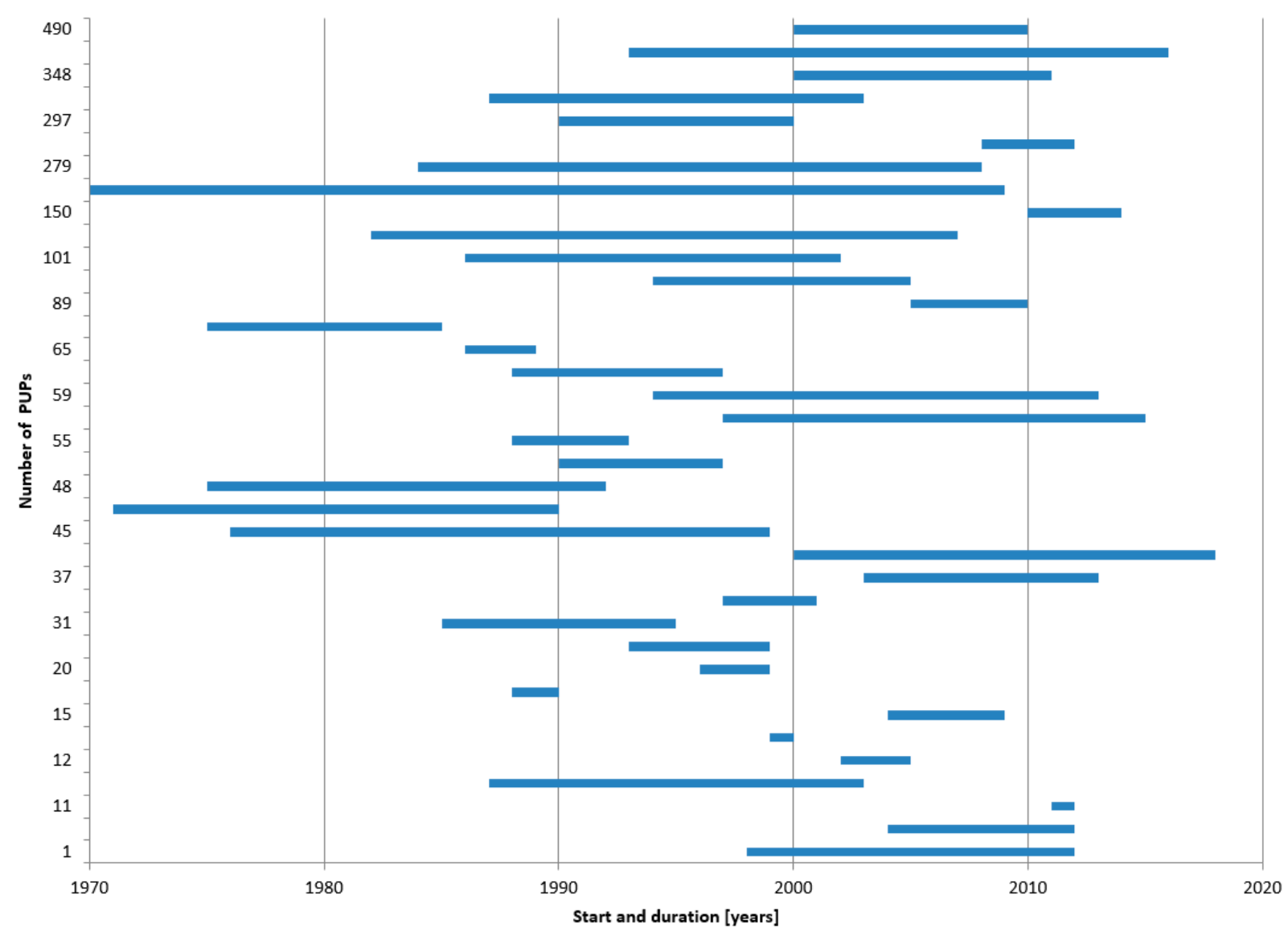

Figure 5. Previously untreated patients (PUP) studies-Number of patients, study start and study duration. Shown are 37 of the 38 publications (for one, the duration could not be found) with the number of recruited patients, the year of study start, and study duration. The publications and underlying data can be found in the Supplement to this paper (File S4).

\subsection{Analysis Results}

Twenty-two studies with high severity disease and any titre inhibitor development in a total of 819 PUPS among 3244 PUPS recruited were eligible for inclusion in the metaanalysis. Combined event rates for any titre inhibitor development ranged from $17 \%$ for plasma-derived products to $26-40 \%$ for recombinant products (Figure 6a). The combined event rate accounted for $28 \%$ (95\% CI: 26-31\%). Overall heterogeneity was high $(\mathrm{Q}=182.61$, $\left.\mathrm{df}=51, p<0.01, \mathrm{I}^{2}=72.07\right)$, and there was a statistically significant difference between the subgroups $(\mathrm{Q}=23.19, \mathrm{df}=6, p<0.01)$ (Figure $6 \mathrm{~b})$.

Within the scope of the second meta-analysis, three studies with a total of 132 PUPS with high severity disease and high titre inhibitor development among 744 PUPS recruited were included. Combined event rates for high titre inhibitor development were estimated to be $12 \%$ (95\% CI: $9-18 \%$ ) for plasma-derived products and $22 \%$ (95\% CI: $18-27 \%)$ for recombinant products (Figure 7a,b). The combined event rate accounted for 19\% (95\% CI: $16-22 \%)$. Overall heterogeneity was high $\left(\mathrm{Q}=21.20, \mathrm{df}=10, p=0.02, \mathrm{I}^{2}=52.82\right)$, and there was also a statistically significant difference between the subgroups $(Q=7.62$, $\mathrm{df}=1, p=0.01$ ). Estimates for different generations of recombinant products were not calculated due to the small number of studies eligible per group. 


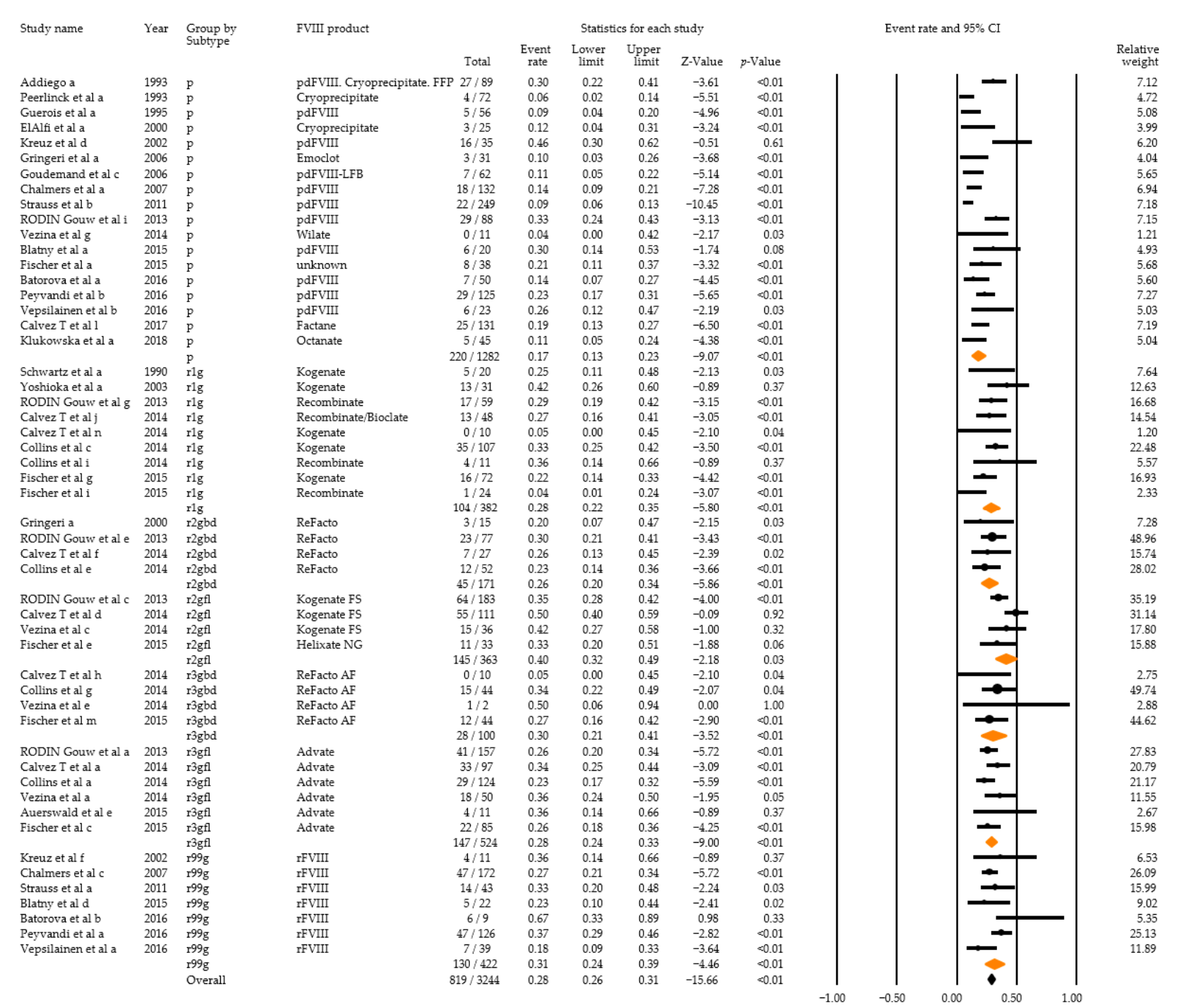

(a)

Figure 6. Cont. 


\begin{tabular}{|c|c|c|c|c|c|c|c|c|c|c|c|c|c|c|}
\hline \multirow{2}{*}{$\begin{array}{l}\text { Groups } \\
\text { Group }\end{array}$} & \multicolumn{4}{|c|}{ Effect size and $95 \%$ interval } & \multicolumn{2}{|c|}{ Test of null (2-Tail) } & \multicolumn{4}{|c|}{ Heterogeneity } & \multicolumn{4}{|c|}{ Tau-squared } \\
\hline & $\begin{array}{c}\text { Number } \\
\text { Studies }\end{array}$ & $\begin{array}{c}\text { Point } \\
\text { Estimate }\end{array}$ & $\begin{array}{c}\text { Lower } \\
\text { Limit }\end{array}$ & $\begin{array}{c}\text { Upper } \\
\text { Limit }\end{array}$ & Z-Value & $p$-Value & Q-Value & df $(Q)$ & $p$-Value & I-Squared & $\begin{array}{c}\text { Tau } \\
\text { Squared }\end{array}$ & $\begin{array}{l}\text { Standard } \\
\text { Error }\end{array}$ & Variance & Tau \\
\hline \multicolumn{15}{|c|}{ Fixed effect analysis } \\
\hline $\mathrm{p}$ & 18 & 0.19 & 0.17 & 0.22 & -18.82 & $<0.01$ & 73.29 & 17 & $<0.01$ & 76.81 & 0.36 & 0.19 & 0.03 & 0.60 \\
\hline $\mathrm{r} 1 \mathrm{~g}$ & 9 & 0.29 & 0.24 & 0.34 & -7.66 & $<0.01$ & 12.30 & 8 & 0.14 & 34.94 & 0.07 & 0.11 & 0.01 & 0.27 \\
\hline $\mathrm{r} 2 \mathrm{gbd}$ & 4 & 0.26 & 0.20 & 0.34 & -5.86 & $<0.01$ & 1.09 & 3 & 0.78 & 0.00 & 0.00 & 0.11 & 0.01 & 0.00 \\
\hline $\mathrm{r} 2 \mathrm{gfl}$ & 4 & 0.40 & 0.35 & 0.45 & -3.71 & $<0.01$ & 6.73 & 3 & 0.08 & 55.44 & 0.07 & 0.11 & 0.01 & 0.26 \\
\hline $\mathrm{r} 3 \mathrm{gbd}$ & 4 & 0.30 & 0.22 & 0.40 & -3.73 & $<0.01$ & 3.17 & 3 & 0.37 & 5.31 & 0.02 & 0.24 & 0.06 & 0.13 \\
\hline r3gfl & 6 & 0.28 & 0.25 & 0.32 & -9.53 & $<0.01$ & 5.43 & 5 & 0.37 & 7.91 & 0.01 & 0.04 & 0.00 & 0.07 \\
\hline $\mathrm{r} 99 \mathrm{~g}$ & 7 & 0.31 & 0.27 & 0.36 & -7.40 & $<0.01$ & 11.73 & 6 & 0.07 & 48.83 & 0.09 & 0.12 & 0.01 & 0.30 \\
\hline Total within & & & & & & & 113.73 & 45 & $<0.01$ & & & & & \\
\hline Total between & & & & & & & 68.88 & 6 & $<0.01$ & & & & & \\
\hline Overall & 52 & 0.27 & 0.26 & 0.29 & -23.48 & $<0.01$ & 182.61 & 51 & $<0.01$ & 72.07 & 0.24 & 0.08 & 0.01 & 0.49 \\
\hline \multicolumn{15}{|c|}{ Mixed effects analysis } \\
\hline $\mathrm{p}$ & 18 & 0.17 & 0.13 & 0.23 & -9.07 & $<0.01$ & & & & & & & & \\
\hline $\mathrm{r} 1 \mathrm{~g}$ & 9 & 0.28 & 0.22 & 0.35 & -5.80 & $<0.01$ & & & & & & & & \\
\hline $\mathrm{r} 2 \mathrm{gbd}$ & 4 & 0.26 & 0.20 & 0.34 & -5.86 & $<0.01$ & & & & & & & & \\
\hline $\mathrm{r} 2 \mathrm{gfl}$ & 4 & 0.40 & 0.32 & 0.49 & -2.18 & 0.03 & & & & & & & & \\
\hline $\mathrm{r} 3 \mathrm{gbd}$ & 4 & 0.30 & 0.21 & 0.41 & -3.52 & $<0.01$ & & & & & & & & \\
\hline r3gfl & 6 & 0.28 & 0.24 & 0.33 & -9.00 & $<0.01$ & & & & & & & & \\
\hline $\mathrm{r} 99 \mathrm{~g}$ & 7 & 0.31 & 0.24 & 0.39 & -4.46 & $<0.01$ & & & & & & & & \\
\hline Total between & & & & & & & 23.19 & 6 & $<0.01$ & & & & & \\
\hline Overall & 52 & 0.28 & 0.26 & 0.31 & -15.66 & $<0.01$ & & & & & & & & \\
\hline
\end{tabular}

(b)

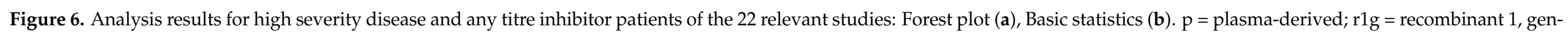

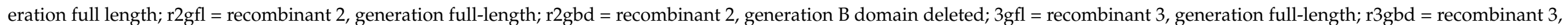
generation B domain deleted; rg99 = recombinant not further specified. 


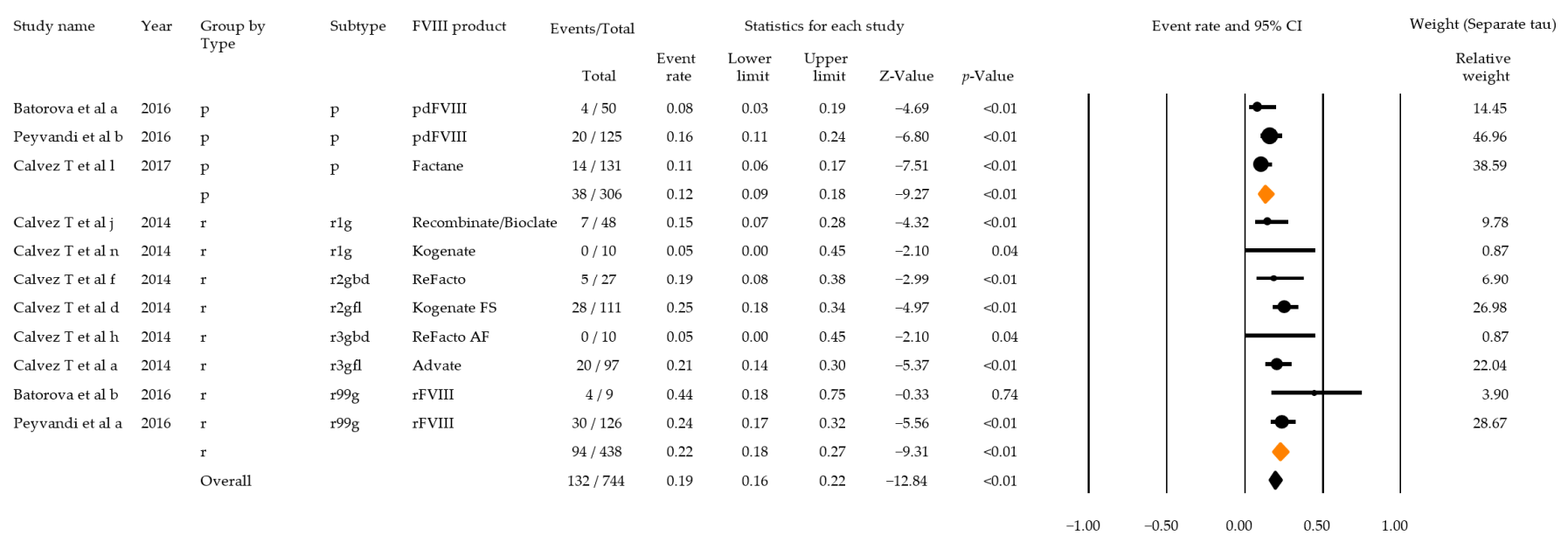

(a)

\begin{tabular}{|c|c|c|c|c|c|c|c|c|c|c|c|c|c|c|}
\hline \multirow{2}{*}{$\begin{array}{l}\text { Groups } \\
\text { Group }\end{array}$} & \multicolumn{4}{|c|}{ Effect Size and $95 \%$ Interval } & \multicolumn{2}{|c|}{ Test of Null (2-Tail) } & \multicolumn{4}{|c|}{ Heterogeneity } & \multicolumn{4}{|c|}{ Tau-Squared } \\
\hline & $\begin{array}{l}\text { Number } \\
\text { Studies }\end{array}$ & $\begin{array}{c}\text { Point } \\
\text { Estimate }\end{array}$ & $\begin{array}{c}\text { Lower } \\
\text { limit }\end{array}$ & $\begin{array}{c}\text { Upper } \\
\text { limit }\end{array}$ & Z-Value & $p$-Value & Q-Value & df $(Q)$ & $p$-value & I-squared & Tau Squared & Standard Error & Variance & Tau \\
\hline \multicolumn{15}{|c|}{ Fixed effect analysis } \\
\hline $\mathrm{p}$ & 3 & 0.13 & 0.09 & 0.17 & -11.04 & $<0.01$ & 2.67 & 2 & 0.26 & 25.12 & 0.03 & 0.14 & 0.02 & 0.19 \\
\hline $\mathrm{r}$ & 8 & 0.22 & 0.19 & 0.27 & -10.63 & $<0.01$ & 8.12 & 7 & 0.32 & 13.79 & 0.02 & 0.08 & 0.01 & 0.14 \\
\hline Total within & & & & & & & 10.79 & 9 & 0.29 & & & & & \\
\hline Total between & & & & & & & 10.41 & 1 & $<0.01$ & & & & & \\
\hline Overall & 11 & 0.19 & 0.16 & 0.22 & -14.98 & $<0.01$ & 21.20 & 10 & 0.02 & 52.84 & 0.13 & 0.12 & 0.01 & 0.35 \\
\hline \multicolumn{15}{|c|}{ Mixed effects analysis } \\
\hline $\mathrm{p}$ & 3 & 0.12 & 0.09 & 0.18 & -9.27 & $<0.01$ & & & & & & & & \\
\hline $\mathrm{r}$ & 8 & 0.22 & 0.18 & 0.27 & -9.31 & $<0.01$ & & & & & & & & \\
\hline Total between & & & & & & & 7.62 & 1 & 0.01 & & & & & \\
\hline Overall & 11 & 0.19 & 0.16 & 0.22 & -12.84 & $<0.01$ & & & & & & & & \\
\hline
\end{tabular}

(b)

Figure 7. Analysis results for high severity disease and high titre inhibitor patients of the three relevant studies that fulfil all parameters as demanded in the ClinGL: Forest plot (a), Basic statistics (b). p = plasma-derived; r recombinant; $\mathrm{r} 1 \mathrm{~g}=$ recombinant 1 , generation full length; $\mathrm{r} 2 \mathrm{gfl}=$ recombinant 2 , generation full-length; $\mathrm{r} 2 \mathrm{gbd}=$ recombinant 2 , generation B domain deleted; $3 \mathrm{gfl}=$ recombinant 3 , generation full-length; $\mathrm{rgbd}=$ recombinant 3 , generation B domain deleted; rg99 = recombinant not further specified.

\section{Discussion}

This systematic review included 38 studies published between 1990 and 2018. The two meta-analyses performed suggested a difference in PUP inhibitor rates between plasmaderived and recombinant FVIII products consistent with other reviews [8-10]. Considering the high heterogeneity, this finding has to be interpreted with caution. In the field of haemophilia research and clinical practice, substantial transformation in methods and knowledge has occurred over the last 40 years. Hence, considerable differences in clinical trials (CTs) carried out in the last decades are not surprising. Triggered by blood products contaminated with HIV and hepatitis C and B at the end of the 1980s and beginning of the 1990s, CTs initially focused on the effective heat inactivation of plasma-derived blood products and the associated virus safety and then, with the emergence of recombinant factor concentrates, on the safety of this new product class. The detection of inhibitors became more and more important, and a refinement of the laboratory methods, on the one hand, and the relevant observation period with the greatest risk of inhibitor development, on the other hand, led to more sophisticated CT designs. The results of early CTs in PUPs led to additional knowledge regarding potential confounding factors, such as the family 
history of inhibitor development, underlying mutation, and intensity of treatment. In addition, the development of Nijmegen's modification of the Bethesda assay in 1995 [58] led to more precise laboratory results and the possibility to reliably differentiate between high and low titre inhibitors. DNA sequencing and its widespread use after automation of the procedure opened up a completely new field of knowledge that allowed linking the type of mutation with the manifestation and severity of HA as well as the potential risk for inhibitor development. This resulted in numerous CTs and observational studies with different study designs, duration of follow-up or frequency of inhibitor testing, including patients with various characteristics and risk factors, and finally impairing a head-to-head comparison of results.

The ClinGL, which came into effect in 2012, was implemented to achieve greater harmonisation and a higher grade of comparability between CTs. However, interpretation of results derived from small, uncontrolled clinical trials is challenging even in the case of harmonisation of study conduct and methodology due to unmeasured potential confounding related to various risk factors for inhibitor development. For seven out of nine FVIII products that seek approval during or after the ClinGL came into effect, CTs enrolling PUPs were initiated, and some of them are still ongoing, while others were completed or terminated (see supplement File S5).

RCTs allocating participants by chance to one or more treatment groups are usually considered as the gold standard to evaluate the efficacy of a therapy. In rare diseases, such as HA, the conduct of RCTs is, however, hampered by methodological and data constraints, such as the limited number of eligible patients (e.g., PUPs) and the geographic dispersion of patients [55]. These constraints of CTs in PUPs finally led to the revision of the ClinGL, waiving the obligation to perform clinical trials in PUPs for marketing authorisation [16].

The revised ClinGL states that both PUPs and previously treated patients (PTPs) should be encouraged to enroll in disease-specific registries [16]. Because a variety of national and international HA registries exist, the ClinGL defined a core parameter set, allowing for data merging [16]. The core data set includes administrative information as well as information on demographics, anamnesis, treatment, inhibitor formation, and relevant concomitant events. Strictly speaking, a registry is a longitudinal prospective observational study. It is able to overcome the " 5 too's" of RCTs that have already been described by Rogers in 1991: too few subjects, too simple in terms of comorbidities or concomitantly administered drugs, too median aged subject pool, too narrow a definition of the clinical condition, and too brief period for evaluation [59]. Whereas registry data better reflects real life, the registry's informative value is restricted by crucial pitfalls, such as selection bias and confounding. Selection bias may arise if participants are not allocated by chance to the study groups. In her recent publication [60], Kathelijn Fischer identified two causes of bias, in particular, when comparing inhibitor incidences from different sources: the risk of patient selection (e.g., risk factors and/or treatment strategies) and information bias (e.g., definitions and/or follow-up). For example, the attending physicians might assign a patient with a very severe clinical picture or pre-existing risk factors for the development of an inhibitor to a more "promising" or "safe" therapy scheme. In addition, recruiting a control group might be a challenge in observational studies since cases and controls should be taken from the same population. Furthermore, selection bias may also be caused by the selective non-participation of individuals. In this case, the reasons for non-participation should be recorded and discussed. Bias due to confounding occurs when a spurious association arises due to a failure to fully adjust for factors related to both the risk factor and outcome. A confounding variable is associated with the exposure and disease under study and may influence both the supposed cause and the supposed effect. Researchers can prevent or correct for confounding by restricting the analysis to individuals without a known confounder by matching, stratification, and using specific statistical procedures (e.g., multiple logistic/cox regression analysis) [61]. However, there is always a risk that so-called "unmeasured" confounding (unknown and/or not recorded confounders) may affect the results of an observational study. 
Overall, the risk of bias for the 38 primary publications was rated low to serious. However, for some studies, little or no information was available regarding bias (Table 1). Due to the lack of respective information, it was not possible to assess the selection bias that may result from the requirement to enroll only PUPs in CTs. In fact, this often leads to the exclusion of patients born in families with a negative family history of HA as well as patients who needed intensive treatment at first exposure. The possible impact of the following known confounders could not be excluded: Ethnicity was described in 28/38 studies, underlying mutation ("genetics") in 19 studies, family history of HA in 21 and family history of inhibitor development in 28 studies. Cox proportional hazard models considering potential confounders were applied only in 11 of 38 primary publications.

Of course, there are established standards and guidelines for the conduct and reporting of observational studies in general, addressing research plan, methods, statistical analysis, discussion, and conclusion that allow addressing and controlling for the most important limitations of these studies [61], but these documents are only partly helpful. Apart from HA-specific registries sharing the same core data set, a common set of agreed minimum standards and guidelines for conducting observational studies on FVIII inhibitor development is required to increase the likelihood of high-quality research and robustness of observational study results. Even with the advent and establishment of novel treatments for HA, such as bypassing agents, FVIII-mimicking agents and gene therapy, these standards and guidelines may help to harmonise research on therapies for HA. Heterogeneity of studies in rare diseases, such as HA, is a major problem in general. As another example, a comparison of studies examining the cost-utility of prophylaxis versus on-demand therapy in HA found that these studies yielded remarkably different results [62]. As noted by the authors, cooperation among key stakeholders is essential to resolve issues outstanding from evidence-based and experimental data, which applies likewise to efficacy and safety assessment of current and emergent HA therapies.

\section{Conclusions}

To conclude, in rare diseases, the number of patients that can be recruited in CTs is limited, and thus, randomised clinical trials for individual products are challenging, in particular, for investigating potential individual risks of individual products. With a 1:1 randomisation and increasing the inhibitor rate from $30 \%$ in control subjects to $40 \%$ under investigational drug, 356 participants would have to be recruited per group to reject the null hypothesis with $80 \%$ power and a Type I error probability of $5 \%$. Therefore, enrolling a sufficient number of patients required for a robust statistical analysis can take a long time. Meanwhile, both laboratory standards and detailed knowledge of the disease may evolve, which ultimately may produce findings that, at the end of the study, are no longer considered state-of-art. Furthermore, additional parameters not collected within the scope of the study may become relevant. Performing a meta-analysis of heterogenic studies to overcome these issues is like shaving cats, dogs, alpaca, rabbits, and sheep and wondering in the end why there is not enough mohair for a pullover.

Finally, what longer-term perspective emerges from this work? This exercise led to a result that is comparable to the results of numerous previous studies and analyses. However, considering the numerous limitations addressed above, these findings are not supportive of decision-making. Which path must be taken to obtain results that are necessary for regulatory decisions? A large network of well-managed registries is seen as the only realistic option, as this would allow the monitoring and investigation of at least those factor concentrates that are actually used in the respective patient groups. Of course, these prerequisites apply equally to other new therapeutic options that are striving to reach the market, such as monoclonal antibodies or gene therapy. Therefore, a commitment of regulators is necessary to carry out a regular analysis or review of the data derived from registries. To achieve this, a well-planned collaboration of registry operators and regulators involving patients and scientists is required, as well as a prior determination and definition of the regulatory measures to be taken when predetermined triggers are exceeded. 
Supplementary Materials: The following are available online at https://www.mdpi.com/1660 $-4601 / 18 / 1 / 225 / s 1$, File S1: Example of a full search in Medline; File S2: An overview of all 80 publications and the assessment process that resulted in the generation of Figure 3; File S3: An overview of the rating process that is summarised in Table 1; File S4: The publications and underlying data that is shown in Figure 5; File S5: Overview of FVIII products that seek approval during or after the ClinGL came into effect.

Author Contributions: Conceptualisation, C.K., A.H., U.D.-B.; methodology, C.K., U.D.-B., D.O.; software, D.O.; formal analysis, D.O.; investigation, C.K., U.D.-B., M.M.-O.; resources, C.K., U.D.-B.; writing-original draft preparation, C.K., U.D.-B., D.O., M.M.-O.; writing-review and editing, C.K., U.D.-B., D.O., M.M.-O., A.H. All authors have read and agreed to the published version of the manuscript.

Funding: This research received no external funding.

Institutional Review Board Statement: Not applicable.

Informed Consent Statement: Not applicable.

Data Availability Statement: The data presented in this study are available in the article (Figures 6 and 7) and in the supplement (Files S2 and S4).

Conflicts of Interest: The authors declare no conflict of interest.

\section{References}

1. $\quad$ van den Berg, H.M.; Fischer, K.; Carcao, M. Timing of inhibitor development in more than 1000 previously untreated patients with severe hemophilia A. Blood 2019, 134, 317-320. [CrossRef] [PubMed]

2. Berntorp, E. Plasma-derived versus recombinant factor concentrates in PUPs: A never ending debate? Hämostaseologie 2017, 37, 53-57. [CrossRef] [PubMed]

3. Lai, J.; Hough, C.; Tarrant, J.; Lillicrap, D. Biological considerations of plasma-derived and recombinant factor VIII immunogenicity. Blood 2017, 129, 3147-3154. [CrossRef] [PubMed]

4. Lieuw, K. Many factor VIII products available in the treatment of hemophilia A: An embarrassment of riches? J. Blood Med. 2017, 8, 67-73. [CrossRef] [PubMed]

5. Gouw, S.C.; Berg, H.M.V.D.; Fischer, K.; Auerswald, G.; Carcao, M.; Chalmers, E.; Chambost, H.; Kurnik, K.; Liesner, R.I.; Petrini, P.; et al. Intensity of factor VIII treatment and inhibitor development in children with severe hemophilia A: The RODIN study. Blood 2013, 121, 4046-4055. [CrossRef] [PubMed]

6. Keipert, C.; Jonker, C.J.; Berg, H.M.V.D.; Hilger, A. Clinical trials and registries in haemophilia: Opponents or collaborators? Comparison of PUP data derived from different data sources. Haemoph. Off. J. World Fed. Hemoph. 2018, 24, 420-428. [CrossRef] [PubMed]

7. Peyvandi, F.; Mannucci, P.M.; Garagiola, I. A Randomized Trial of Factor VIII and Neutralizing Antibodies in Hemophilia A. N. Engl. J. Med. 2016, 374, 2054-2064. [CrossRef] [PubMed]

8. Messori, A.; Peyvandi, F.; Mengato, D.; Mannucci, P.M. Incidence of low-titre factor VIII inhibitors in patients with haemophilia A: Meta-analysis of observational studies. Haemoph. Off. J. World Fed. Hemoph. 2017, 23, e87-e92. [CrossRef]

9. Rota, M.; Cortesi, P.A.; Steinitz-Trost, K.N.; Reininger, A.J.; Gringeri, A.; Mantovani, L.G. Meta-analysis on incidence of inhibitors in patients with haemophilia A treated with recombinant factor VIII products. Blood Coagul. Fibrinolysis 2017, 28, 627-637. [CrossRef]

10. Franchini, M.; Coppola, A.; Rocino, A. Systematic review of the role of FVIII concentrates in inhibitor development in pre-viously untreated patients with severe hemophilia a: A 2013 update. Semin. Thromb. Hemost. 2013, 39, 752-766.

11. European Medicines Agency. CHMP Confirms PRAC Recommendations on Kogenate Bayer/Helixate NexGen: Benefits Continue to Outweigh Risks in Previously Untreated Patients (EMA/781158/2013). 2013. Available online: https://www.ema.europa.eu/ en/documents / press-release/chmp-confirms-prac-recommendations-kogenate-bayer/helixate-nexgen_en.pdf (accessed on 22 September 2020).

12. European Medicines Agency. Review of Kogenate Bayer/Helixate NexGen Started: EMA/136663/2013. 2013. Available online: https: / www.ema.europa.eu/en/documents / referral/kogenate-bayer-helixate-nexgen-article-20-procedure-reviewstarted_en.pdf (accessed on 22 September 2020).

13. European Medicines Agency. Review of Factor VIII Medicines and Risk of Developing Inhibitors in Patients Starting Treatment for Haemophilia A: EMA/472176/2016. 2016. Available online: https:/ /www.ema.europa.eu/en/documents/referral/factorviii-article-31-referral-review-started_en.pdf (accessed on 22 September 2020).

14. European Medicines Agency. Factor VIII Medicines: No Clear and Consistent Evidence of Difference in Risk of Inhibitor Development between Classes: EMA Concludes Review of Human Factor VIII Medicines Authorised in EU (EMA/765710/2017); European Medicines Agency: Amsterdam, The Netherlands, 2017. 
15. European Medicines Agency. Guideline on core SmPC for Human Plasma Derived and Recombinant Coagulation Factor VIII Products rev. 3 (EMA/CHMP/BPWP/1619/1999 rev. 3). 2018. Available online: https://www.ema.europa.eu/en/documents/ scientific-guideline/guideline-core-smpc-human-plasma-derived-recombinant-coagulation-factor-viii-products-revision-3_ en.pdf (accessed on 22 September 2020).

16. European Medicines Agency. Guideline on the Clinical Investigation of Recombinant and Human Plasma-Derived Factor VIII Products (EMA/CHMP/BPWP/144533/2009 rev. 1). 2016. Available online: https://www.ema.europa.eu/en/documents/ scientific-guideline/guideline-clinical-investigation-recombinant-human-plasma-derived-factor-viii-products-revision-1_en. pdf (accessed on 22 September 2020).

17. European Medicines Agency. Guideline on the Clinical Investigation of Recombinant and Human Plasma-Derived Factor VIII Products (EMA/CHMP/BPWP/144533/2009 rev. 2). 2018. Available online: https:/ /www.ema.europa.eu/en/documents/ scientific-guideline/guideline-clinical-investigation-recombinant-human-plasma-derived-factor-viii-products-revision-2_en. pdf (accessed on 22 September 2020).

18. Paul-Ehrlich-Institut. Coagulation Factors. Available online: https://www.pei.de/EN/medicinal-products/blood-products/ coagulation-factors/coagulation-factors-node.html (accessed on 22 September 2020).

19. Sterne, J.A.C.; Higgins, J.P.T.; Reeves, B.C.; on Behalf of the Development Group for ACROBAT-NRSI. A Cochrane Risk of Bias Assessment Tool: For Non-Randomized Studies of Interventions (ACROBAT-NRSI): Version 1.0.0, 24 September 2014. Available online: http:/ / www.riskofbias.info (accessed on 2 October 2018).

20. Huedo-Medina, T.B.; Sánchez-Meca, J.; Marín-Martínez, F.; Botella, J. Assessing heterogeneity in meta-analysis: Q statistic or $\mathrm{I}^{2}$ index? Psychol. Methods 2006, 11, 193-206. [CrossRef] [PubMed]

21. Calvez, T.; Chambost, H.; Claeyssens-Donadel, S. Recombinant factor VIII products and inhibitor development in previ-ously untreated boys with severe hemophilia A. Blood 2014, 124, 3398-3408. [CrossRef]

22. Batorova, A.; Jankovicova, D.; Morongova, A.; Bubanska, E.; Prigancova, T.; Horakova, J.; Machyniakova, M.; Červenka, J.; Chandoga, J.; Böhmer, D.; et al. Inhibitors in Severe Hemophilia A: 25-Year Experience in Slovakia. Semin. Thromb. Hemost. 2016, 42, 550-562. [CrossRef]

23. Auerswald, G.; Thompson, A.A.; Recht, M. Experience of Advate rAHF-PFM in previously untreated patients and mini-mally treated patients with haemophilia A. Thromb. Haemost. 2012, 107, 1072-1082. [PubMed]

24. Auerswald, G.; Kurnik, K.; Aledort, L.M.; Chehadeh, H.; Loew-Baselli, A.; Steinitz, K.; Reininger, A.J. The EPIC clinical study group The EPIC study: A lesson to learn. Haemoph. Off. J. World Fed. Hemoph. 2015, 21, 622-628. [CrossRef] [PubMed]

25. Biasi, R.d.; Rocino, A.; Papa, M.L.; Salerno, E.; Mastrullo, L.; Blasi, D.d. Incidence of factor VIII inhibitor development in hemo-philia A patients treated with less pure plasma derived concentrates. Thromb. Haemost. 1994, 71, 544-547. [PubMed]

26. Bray, G.L.; Gomperts, E.D.; Courter, S.; Gruppo, R.; Gordon, E.M.; Manco-Johnson, M.; Shapiro, A.; Scheibel, E.; White, G.; Lee, M. A multicenter study of recombinant factor VIII (recombinate): Safety, efficacy, and inhibitor risk in previously untreated patients with hemophilia A. The Recombinate Study Group. Blood 1994, 83, 2428-2435.

27. Courter, S.G.; Bedrosian, C.L. Clinical evaluation of B-domain deleted recombinant factor VIII in previously untreated patients. Semin. Hematol. 2001, 38, 52-59. [CrossRef]

28. El Alfy, M.S.; Tantawy, A.A.G.; Ahmed, M.H.; Abdin, I.A. Frequency of inhibitor development in severe haemophilia A children treated with cryoprecipitate and low-dose immune tolerance induction. Haemoph. Off. J. World Fed. Hemoph. 2000, 6, 635-638. [CrossRef]

29. Guérois, C.; Laurian, Y.; Rothschild, C.; Parquet-Gernez, A.; Duclos, A.M.; Negrier, C.; Vicariot, M.; Fimbel, B.; Fressinaud, E.; Fiks-Sigaud, M. Incidence of factor VIII inhibitor development in severe hemophilia A patients treated only with one brand of highly purified plasma-derived concentrate. Thromb. Haemost. 1995, 73, 215-218. [CrossRef]

30. Klukowska, A.; Komrska, V.; Vdovin, V. Low incidence of factor VIII inhibitors in previously untreated patients with se-vere haemophilia A treated with octanate ${ }^{\circledR}$ : Final report from a prospective study. Haemoph. Off. J. World Fed. Hemoph. 2018, 24, 221-228. [CrossRef] [PubMed]

31. Kreuz, W.; Gill, J.C.; Rothschild, C. Full-length sucrose-formulated recombinant factor VIII for treatment of previously un-treated or minimally treated young children with severe haemophilia A: Results of an international clinical investigation. Thromb. Haemost. 2005, 93, 457-467.

32. Kreuz, W.; Ettingshausen, C.E.; Zyschka, A.; Oldenburg, J.; Martinez-Saguer, I.; Ehrenforth, S.; Klingebiel, T. Inhibitor Development in Previously Untreated Patients with Hemophilia A: A Prospective Long-Term Follow-Up Comparing Plasma-Derived and Recombinant Products. Semin. Thromb. Hemost. 2002, 28, 285-290. [CrossRef] [PubMed]

33. Lusher, J.M.; Salzman, P.M. Viral safety and inhibitor development associated with factor VIIIC ultra-purified from plasma in hemophiliacs previously unexposed to factor VIIIC concentrates. The Monoclate Study Group. Semin. Hematol. 1990, $27,1-7$.

34. Lusher, J.; Abildgaard, C.; Arkin, S. Human recombinant DNA-derived antihemophilic factor in the treatment of previous-ly untreated patients with hemophilia A: Final report on a hallmark clinical investigation. J. Thromb. Haemo-Stasis JTH 2004, 2, 574-583. [CrossRef] [PubMed]

35. Matysiak, M.; Bobrowska, H.; Balwierz, W.; Chybicka, A.; Kowalczyk, J.; Shaikh-Zaidi, R.; Gillanders, K.; Dash, C.H. Clinical experience with Optivate ${ }^{\circledR}$, high-purity factor VIII (FVIII) product with von Willebrand factor (VWF) in young children with haemophilia A. Haemoph. Off. J. World Fed. Hemoph. 2011, 17, 737-742. [CrossRef] [PubMed] 
36. Schwartz, R.S.; Abildgaard, C.F.; Aledort, L.M.; Arkin, S.; Bloom, A.L.; Brackmann, H.H.; Brettler, D.B.; Fukui, H.; Hilgartner, M.W.; Inwood, M.J.; et al. Human Recombinant DNA-Derived Antihemophilic Factor (Factor VIII) in the Treatment of Hemophilia A. New Engl. J. Med. 1990, 323, 1800-1805. [CrossRef]

37. Yee, T.T.; Williams, M.D.; Hill, F.G.; Lee, C.A.; Pasi, K.J. Absence of inhibitors in previously untreated patients with severe haemo-philia A after exposure to a single intermediate purity factor VIII product. Thromb. Haemost. 1997, 78, 1027-1029.

38. Yoshioka, A.; Fukutake, K.; Takamatsu, J.; Shirahata, A. Clinical evaluation of a recombinant factor VIII preparation (Kogenate) in previously untreated patients with hemophilia A. Int. J. Hematol. 2003, 78, 467-474. [CrossRef]

39. Addiego, J.; Kasper, C.; Abildgaard, C.; Hilgartner, M.; Lusher, J.; Glader, B.; Aledort, L. Frequency of inhibitor development in haemophiliacs treated with low-purity factor VIII. Lancet 1993, 342, 462-464. [CrossRef]

40. Blatny, J.M.; Komrska, V.; Blažek, B.; Penka, M.; Ovesná, P. Inhibitors incidence rate in Czech previously untreated patients with haemophilia A has not increased since introduction of recombinant factor VIII treatment in 2003. Blood Coagul. Fibrinolysis 2015, 26, 673-678. [CrossRef] [PubMed]

41. Calvez, T.; Chambost, H.; D’Oiron, R.; Dalibard, V.; DeMiguel, V.; Doncarli, A.; Gruel, Y.; Huguenin, Y.; Lutz, P.; Rothschild, C.; et al. Analyses of the FranceCoag cohort support differences in immunogenicity among one plasmaderived and two recombinant factor VIII brands in boys with severe hemophilia A. Haematologica 2017, 103, 179-189. [CrossRef] [PubMed]

42. Chalmers, E.A.; Brown, S.A.; Keeling, D.; Liesner, R.; Richards, M.; Stirling, D.; Thomas, A.; Vidler, V.; Williams, M.D.; Young, D. Early factor VIII exposure and subsequent inhibitor development in children with severe haemophilia A. Haemoph. Off. J. World Fed. Hemoph. 2007, 13, 149-155. [CrossRef] [PubMed]

43. Collins, P.W.; Palmer, B.P.; Chalmers, E.A. Factor VIII brand and the incidence of factor VIII inhibitors in previously un-treated UK children with severe hemophilia A, 2000-2011. Blood 2014, 124, 3389-3397. [CrossRef]

44. Fischer, K.; Lassila, R.; Peyvandi, F. Inhibitor development in haemophilia according to concentrate. Four-year results from the European HAemophilia Safety Surveillance (EUHASS) project. Thromb. Haemost. 2015, 113, 968-975. [PubMed]

45. Goudemand, J.; Rothschild, C.; DeMiguel, V.; Vinciguerrat, C.; Lambert, T.; Chambost, H.; Borel-Derlon, A.; Claeyssens, S.; Laurian, Y.; Calvez, T.; et al. Influence of the type of factor VIII concentrate on the incidence of factor VIII inhibitors in previously untreated patients with severe hemophilia A. Blood 2006, 107, 46-51. [CrossRef] [PubMed]

46. Gouw, S.; van der Bom, J.; Auerswald, G.; Escuriola Ettinghausen, C.; Tedgård, U.; van den Berg, H.M. Recombinant versus plas-ma-derived factor VIII products and the development of inhibitors in previously untreated patients with severe hemophilia A: The CANAL cohort study. Blood 2007, 109, 4693-4697. [CrossRef] [PubMed]

47. Gringeri, A.; Tagariello, G.; Mannucci, P.M. A safety survey of inhibitor development on all of 130 italian users of the b-domain deleted recombinant factor VIII (BDDrFVIII) Refacto. Blood 2000, 96, 262A.

48. Gringeri, A.; Monzini, M.; Tagariello, G.; Scaraggi, F.A.; Mannucci, P.M. Occurrence of inhibitors in previously untreated or mini-mally treated patients with haemophilia A after exposure to a plasma-derived solvent-detergent factor VIII concentrate. Haemoph. Off. J. World Fed. Hemoph. 2006, 12, 128-132. [CrossRef] [PubMed]

49. Kurnik, K.; Halimeh, S.; Manner, D.; Holzhauer, S.; Ettingshausen, C.E.; Schobess, R.; Nowak-Gottl, U. Impact of Treatment Intensity and Factor VIII Products On the Development On High Titre Inhibitors in Children with Severe Hemophilia A: Results of a Non-Concurrent Cohort Study. Blood 2009, 114, 1303. [CrossRef]

50. Maak, B.; Nimtz-Talaska, A.; Nowak-Göttl, U.; Kentouche, K.; Schulze, M.; Wolf, H.; Schubert, C.; Halimeh, S.; Syrbe, G.; Eifrig, B.; et al. (Eds.) Treatment of Hemophilia A Patients with FAKTOR VIII SDH INTERSERO: Interim Report of a Long-Time Post-Marketing Pharmacovigilance. 56th Annual Meeting of the Society of Thrombosis and Haemostasis Research, Abstract No: P2-5. 2012. Available online: https://www.yumpu.com/en/document/read/4475236/poster-prasentationen-posterpresentations-po (accessed on 29 December 2020).

51. Mancuso, M.E.; Mannucci, P.M.; Rocino, A.; Garagiola, I.; Tagliaferri, A.; Santagostino, E. Source and purity of factor VIII products as risk factors for inhibitor development in patients with hemophilia A. J. Thromb. Haemost. 2012, 10, 781-790. [CrossRef] [PubMed]

52. Musso, R.; Santagostino, E.; Faradji, A. Safety and efficacy of sucrose-formulated full-length recombinant factor VIII: Expe-rience in the standard clinical setting. Thromb. Haemost. 2008, 99, 52-58. [PubMed]

53. Oldenburg, J.; Goudemand, J.; Valentino, L. Postauthorization safety surveillance of ADVATE antihaemophilic factor (recombinant), plasma/albumin-free method demonstrates efficacy, safety and low-risk for immunogenicity in routine clinical practice. Haemoph. Off. J. World Fed. Hemoph. 2010, 16, 866-877. [CrossRef] [PubMed]

54. Peerlinck, K.; Rosendaal, F.R.; Vermylen, J. Incidence of inhibitor development in a group of young hemophilia A patients treated exclusively with lyophilized cryoprecipitate. Blood 1993, 81, 3332-3335. [CrossRef]

55. Strauss, T.; Lubetsky, A.; Ravid, B.; Bashari, D.; Luboshitz, J.; Lalezari, S.; Misgav, M.; Martinowitz, U.; Kenet, G. Recombinant factor concentrates may increase inhibitor development: A single centre cohort study. Haemoph. Off. J. World Fed. Hemoph. 2011, 17, 625-629. [CrossRef]

56. Vepsalainen, K.; Lassila, R.; Arola, M.; Huttunen, P.; Koskinen, S.; Ljung, R.; Lähteenmäki, P.M.; Möttönen, M.; Riikonen, P. Inhibitor development in previously untreated patients with severe haemophilia A: A nationwide multicentre study in Finland. Haemoph. Off. J. World Fed. Hemoph. 2016, 22, 721-729. [CrossRef] 
57. Vézina, C.; Carcao, M.; Infante-Rivard, C.; Lillicrap, D.; Stain, A.M.; Paradis, E.; Teitel, J.; Rivard, G.E.; the Association of Hemophilia Clinic Directors of Canada and of the Canadian Association of Nurses in Hemophilia Care. Incidence and risk factors for inhibitor development in previously untreated severe haemophilia A patients born between 2005 and 2010. Haemoph. Off. J. World Fed. Hemoph. 2014, 20, 771-776. [CrossRef]

58. Verbruggen, B.; Novakova, I.; Wessels, H.; Boezeman, J.; Berg, M.V.D.; Mauser-Bunschoten, E. The Nijmegen modification of the Bethesda assay for factor VIII:C inhibitors: Improved specificity and reliability. Thromb. Haemost. 1995, 73, 247-251. [CrossRef]

59. Hartzema, A.G.; Porta, M.S. Unintended drug effects: Identification and attribution. In Pharmacoepidemiology: An introduction, 2nd ed.; Harvey Whitney Books: Cincinnati, OH, USA, 1991.

60. Fischer, K. Interpreting data on inhibitor development from previously untreated patient studies, beware of premature conclusions. Haemoph. Off. J. World Fed. Hemoph. 2018, 24, 177-179. [CrossRef]

61. The European Network of Centres for Pharmacoepidemiology and Pharmacovigilance (ENCePP). Guide on Methodological Standards in Pharmacoepidemiology (Revision 8). EMA/95098/. Available online: http://www.encepp.eu/standards_and_ guidance (accessed on 22 September 2020).

62. Valente, M.; Cortesi, P.A.; Lassandro, G.; Mathew, P.; Pocoski, J.; Molinari, A.C.; Mantovani, L.G.; Giordano, P. Health economic mod-els in hemophilia A and utility assumptions from a clinician's perspective. Pediatric Blood Cancer 2015, 62, 1826-1831. [CrossRef] 